Pacific Journal of Mathematic 


\title{
BOOLEAN ALGEBRAS WITH PATHOLOGICAL ORDER TOPOLOGIES
}

\author{
E. E. FLOYD
}

If $L$ is a partially ordered set, there are a variety of known ways in which $L$ may be given a topology compatible, in some sense, with its partial ordering (see $[1,6]$ ). Examples, by Northam [3] and Floyd and Klee [2], have very recently appeared of complete lattices which are not Hausdorff in their order topologies. It appears, then, that the various topologies will not be central in the study of all complete lattices. The question remains as to whether or not there is some wide and natural class of lattices in which some compatible topology has nice properties. We give a very simple example of a complete Boolean algebra which is not Hausdorff in any topology compatible with the order. We also give an example of a conditionally complete vector lattice in which addition is not continuous in any compatible topology. This is a counterexample to a result of Birkhoff [1, p. 242], who overlooked the possibility that convergence in the order topology differs from order convergence.

Definition. Suppose that $(P, \geq)$ is a partially ordered set, and suppose that $T$ is a topology for the set $P$ (that is, $T$ is a collection of subsets of $P$ closed under arbitrary unions and finite intersections, and with $\phi \in T, P \in T$ ). We say that $T$ is $\sigma$-compatible with $\geq$ if and only if whenever $\left(x_{i}\right)$ is a sequence in $P$ with

$$
x_{1} \geq x_{2} \geq \cdots \text { and } \bigwedge_{i} x_{i}=x
$$

or

$$
x_{1} \leq x_{2} \leq \cdots \text { and } \bigvee_{i} x_{i}=x,
$$

then the sequence $\left(x_{i}\right) T$-converges to $x$.

THEOREM 1. Let $L$ denote the complete Boolean algebra of all regular open subsets of the unit interval I, partially ordered by inclusion $>$. Suppose that $T$ is a topology for $L$ which is $\sigma$-compatible with $>$. Then the topology $T$ is not Hausdorff.

Proof. Recall that a subset $b$ of $I$ is a regular open set if and only if $b$ is the interior of its closure. $L$ is known to be a complete

Received January 11, 1954. This research was supported by National Science Foundation Grant, NSF-G358. 
Boolean algebra [1]. Let $\mathscr{U}$ be a $T$-neighbourhood of the empty set $\phi \in L$. We show that $I \in \overline{\mathscr{Z}}$. Suppose that $U_{1}, U_{2}, \cdots$, is a basis for the open sets of 1 , with each $U_{i}$ nonempty. There exists for each $i$ a sequence $\left(A_{j}^{i} \mid j=1,2, \cdots\right)$ in $L$ with

$$
A_{j}^{i} \subset U_{i}, A_{j}^{i} \subsetneq \phi,
$$

so that $A_{1}^{i}>A_{2}^{i}>\cdots$ and

$$
\bigwedge\left(A_{j}^{i} \mid j=1,2, \cdots\right)=\phi .
$$

Since $\left(A_{i}^{1}\right)$ converges to $\phi$, there exists $A_{i}^{1} \in \mathscr{U}$. Define $B_{1}=A_{i}^{1}$. Since the sequence $\left(B_{1} \bigvee A_{j}^{2}\right)$ converges to $B_{1}$, there exists $j$ with $B_{1} \bigvee A_{j}^{2} \in \mathscr{U}$. Define $B_{2}=B_{1} \bigvee A_{j}^{2}$. Similarly there exists $B_{3}=B_{2} \bigvee A_{k}^{3} \in \mathscr{C}, \ldots$. Now $\left(B_{i}\right)$ is a sequence in $\mathscr{U}$ with $B_{1}<B_{2}<\ldots$. Moreover, since the only regular open set containing $\cup B_{i}$ is $I$, we have $\vee_{i} B_{i}=I$. Hence $I \in \overline{\mathscr{U}}$ and the theorem follows.

The following remark answers Problem 77 of Birkhoff [1, p. 167].

THEOREM 2. If $L$ is the complete Boolean algebra of Theorem 1, then there exist, for $i=1,2 \cdots$, sequences $\left(X_{i, j} \mid j=1,2, \cdots\right)$ with $\left(X_{i, j}\right)$ order-converging to $\phi$ for each $i$ but such that for no function $j(i)$ is it true that $\left(X_{i, j(i)}\right)$ order-converges to $\phi$.

Proof. Let $\left(X_{i, j}\right)$ denote the sequence $\left(A_{j}^{i}\right)$ of the proof of Theorem 1 . Consider any function $j(i)$, then

$$
\bigvee_{i \geq k} A_{j(i)}^{i}=I
$$

Hence

$$
\bigwedge_{k} \bigvee_{i \geq k} A_{j(i)}^{i}=I
$$

Hence the sequence $\left(X_{i, j(i)}\right)$ does not order-converge to $\phi$.

THEOREM 3. Let $L$ be the complete Boolean algebra of Theorem 1, and let $M$ be a Stone representation space for $L$. Let $N$ denote the lattice of all continuous real-valued functions on $M$. Then $N$ is a conditionally complete vector lattice in which the function $x-y$ is not $T$-continuous simultaneously in $x$ and $y$ for any $T_{1}$-topology $T$ for $N$ which is $\sigma$-compatible with $>$.

Proof. It is known $[4,7]$ that $N$ is conditionally complete. We may consider $L$ as identical with the algebra of all open and closed subsets of $M$. There is a function $t: L \rightarrow N$ which assigns to $u \in L$ the 
characteristic function $t(u)$ of the open and closed set $u$. We show that $t$ is an embedding of $L$ in $N$. It is seen that $t$ is an isotone oneto-one map of $L$ onto $t(L)$, and $t^{-1}$ is an isotone map of $t(L)$ on $L$. We prove that if $K \subset L$ then

$$
\vee t(K)=t(\bigvee K)
$$

where $\vee t(K)$ denotes the least upper bound in $N$. Clearly

$$
t(\vee K) \geq \bigvee t(K) \text {. }
$$

Now $\vee t(K)$ is a nonnegative continuous function whose value is $\geq 1$ on the set $\cup K$, and hence $\geq 1$ also on its closure. But the closure of $\cup K$ is $\vee K[7]$. Hence

$$
t(\vee K) \leq \vee t(K)
$$

and equality holds. The dual also follows. So $t$ embeds $L$ in $N$. It follows that $t(L)$ is not Hausdorff in the topology $T$ restricted to $t(L)$. Hence $N$ is not Hausdorff in the topology $T$. But if $x-y$ is $T$-continuous in $x$ and $y$, it is known that $N$ is then regular [5, p. 54] and hence Hausdorff.

Corollary. Suppose, in addition to the hypotheses of Theorem 3, that the function $y \rightarrow-y$ on $N$ is T-continuous. Then $x+y$ is not $T$ continuous in $x$ and $y$ simultaneously.

This answers, in the negative, a part of Problem 4 of Rennie $[6$, p. 51].

\section{REFERENCES}

1. G. Birkhoff, Lattice theory, New York, 1948.

2. E. E. Floyd and V. L. Klee, A characterization of reflexivity by the lattice of closed subspaces, Proc. Amer. Math. Soc. 5 (1954), 655-661.

3. E. S. Northam, Topology in lattices, Bull. Amer. Math. Soc., 59 (1953), 387.

4. T. Ogasawara, Theory of vector lattices, I. J. Sci. Hirosima Univ. Ser. A 12 (1942), $37-100$.

5. L. Pontrjagin, Topological groups, Princeton, 1946.

6. B. C. Rennie, The theory of lattices, Cambridge, 1951.

7. M. H. Stone, Boundedness properties in function lattices, Canadian J. Math., 1 (1949), $176-186$. 



\section{PACIFIC JOURNAL OF MATHEMATICS}

\section{EDITORS}

\author{
H. L. Royden \\ Stanford University \\ Stanford, California \\ E. Hewite \\ University of Washington \\ Seattle 5 , Washington
}

\author{
R. P. Dilworth
}

California Institute of Technology Pasadena 4, California

\section{A. HorN*}

University of California

Los Angeles 24, California

\section{ASSOCIATE EDITORS}

\author{
H. BUSEMANN \\ HERBERT FEDERER \\ MARSHALL HALL
}

\author{
P. R. HALMOS \\ HEINZ HOPF \\ ALFRED HORN
}

\author{
R. D. JAMES \\ BORGE JESSEN \\ PAUL LÉVY
}

GEORGE PÓLYA

J. J. STOKER

KOSAKU YOSIDA

\section{SPONSORS}

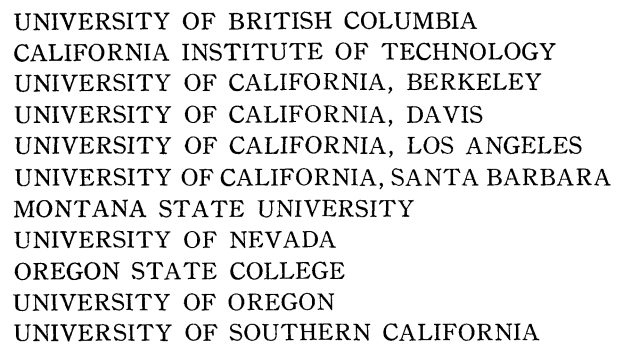

UNIVERSITY OF BRITISH COLUMBIA

CALIFORNIA INSTITUTE OF TECHNOLOGY

UNIVERSITY OF CALIFORNIA, BERKELEY

UNIVERSITY OF CALIFORNIA, DAVIS

UNIVERSITY OF CALIFORNIA, LOS ANGELES

UNIVERSITY OF CALIFORNIA, SANTA BARBARA

MONTANA STATE UNIVERSITY

UNIVERSITY OF NEVADA

OREGON STATE COLLEGE

UNIVERSITY OF OREGON

UNIVERSITY OF SOUTHERN CALIFORNIA

\author{
STANFORD RESEARCH INSTITUTE \\ STANFORD UNIVERSITY \\ UNIVERSITY OF UTAH \\ WASHINGTON STATE COLLEGE \\ UNIVERSITY OF WASHINGTON
}

AMERICAN MATHEMATICAL SOCIETY

HUGHES AIRCRAFT COMPANY SHELL DEVELOPMENT COMPANY

Mathematical papers intended for publication in the Pacific Journal of Mathematics should be typewritten (double spaced), and the author should keep a complete copy. Manuscripts may be sent to any of the editors. Manuscripts intended for the outgoing editors should be sent to their successors. All other communications to the editors should be addressed to the managing editor, Alfred Horn at the University of California Los Angeles 24, California.

50 reprints of each article are furnished free of charge; additional copies may be obtained at cost in multiples of 50 .

The Pacific Journal of Mathematics is published quarterly, in March, June, September, and December. The price per volume (4 numbers) is $\$ 12.00$; single issues, $\$ 3.50$; back numbers (Volumes $1,2,3)$ are available at $\$ 2.50$ per copy. Special price to individual faculty members of supporting institutions and to individual members of the American Mathematical Society: $\$ 4.00$ per volume; single issues, $\$ 1.25$.

Subscriptions, orders for back numbers, and changes of address should be sent to the publishers, University of California Press, Berkeley 4, California.

Printed at Kokusai Bunken Insatsusha (International Academic Printing Co., Ltd.) No. 10 1-chome Fujimi-cho, Chiyoda-ku, Tokyo, Japan.

* During the absence of E. G. Straus. 


\section{Pacific Journal of Mathematics}

\section{Vol. 5, No. $5 \quad$ BadMonth, 1955}

Henry A. Antosiewicz, A theorem on alternatives for pairs of matrice . . . . . 641

F. V. Atkinson, On second-order non-linear oscillation ............... 643

Frank Herbert Brownell, III, Fourier analysis and differentiation over real separable Hilbert spac .................................. 649

Richard Eliot Chamberlin, Remark on the averages of real function ...... 663

Philip J. Davis, On a problem in the theory of mechanical quadrature ... . . 669

Douglas Derry, On closed differentiable curves of order $n$ in $n$-spac ...... 675

Edwin E. Floyd, Boolean algebras with pathological order topologie ... . . 687

George E. Forsythe, Asymptotic lower bounds for the fundamental frequency of convex membrane ................................. 691

Israel Halperin, On the Darboux propert ................... 703

Theodore Edward Harris, On chains of infinite orde .............. 707

Peter K. Henrici, On certain series expansions involving Whittaker functions

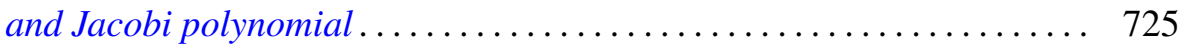

John G. Herriot, The solution of Cauchy's problem for a third-order linear hyperoblic differential equation by means of Riesz integral ......... 745

Jack Indritz, Applications of the Rayleigh Ritz method to variational

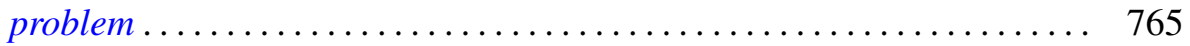

E. E. Jones, The flexure of a non-uniform bea ................. 799

Hukukane Nikaidô and Kazuo Isoda, Note on non-cooperative convex game.

Raymond Moos Redheffer and W. Wasow, On the convergence of asymptotic solutions of linear differential equation . . .

S. E. Warschawski, On a theorem of L. Lichtenstei ...........

Philip Wolfe, The strict determinateness of certain infinite game... 